\title{
Kombucha multimicrobial community under simulated space-flight and Martian conditions
}

${ }^{1}$ O.Podolich, ${ }^{1}$ I.Zaets, ${ }^{1}$ O.Kukharenko, ${ }^{1}$ I.Orlovska, ${ }^{2}$ O.Reva, ${ }^{3}$ L.Khirunenko, ${ }^{3}$ M.Sosnin, ${ }^{1}$ Haidak A.,

${ }^{1}$ S.Shpylova, ${ }^{4}$ E.Rabbow, ${ }^{5}$ M.Skoryk, ${ }^{5}$ M.Kremenskoy, ${ }^{6}$ R.Demets, ${ }^{1}$ N.Kozyrovska, ${ }^{7}$ J.-P.de Vera

${ }^{1}$ Institute of Molecular Biology \& Genetics of NASU, Kyiv, Ukraine, kozyrna@ukr.net

${ }^{2}$ Pretoria University, Bioinformatics Center, South Africa

${ }^{3}$ Institute of Physics of NASU, Kyiv, Ukraine

${ }^{4}$ German Aerospace Center (DLR) Cologne, Institute of Aerospace Medicine, Radiation Biology, FRG

${ }^{5}$ NanoMedTech LLC, Kyiv, Ukraine

${ }^{6}$ ESA/ESTEC, Noordwijk, The Netherlands

${ }^{7}$ German Aerospace Center (DLR) Berlin, Institute of Planetary Research, FRG

* Corresponding author: Olga Podolich, Institute of Molecular Biology and Genetics of NASU, Acad. Zabolotnoho str., 150, 03680 Kyiv, Ukraine, Tel.:+380445265596; Fax: +380445260759; Email: podololga@ukr.net

Abstract. Kombucha microbial community (KMC) produces cellulose_based biopolymer of industrial importance and probiotic beverages. KMC-derived cellulose-based pellicle film is known as a highly adaptive microbial macrocolony - a stratified community of pro- and eukaryotes. In the framework of the multipurpose international astrobiological project "BIOlogical and Mars Experiment (BIOMEX)", which aims to study vitality of pro- and eukaryotic organisms and stability of selected biomarkers in low Earth orbit and in an Mars-like environment, a cellulose polymer structural integrity will be assessed as a biomarker and biotechnological nanomaterial. In the pre-flight assessment programs for BIOMEX, the mineralized bacterial cellulose did not exhibit significant changes in the structure under all types of tests. KMC-members, inhabiting the cellulose-based pellicle, demonstrated high survival rate; however, the survival capacity depended on types of stressors such as space vacuum, Mars-like atmosphere, UV-C radiation, temperature fluctuations. The critical limiting factor for microbial survival was high-dose UVirradiation. In the tests simulating one-year mission exposure, the core populations of bacteria and yeasts have survived provided protection against UV; however, the microbial density of the populations reduced that was shown by culture-depended and culture-independent methods. Reduction of microbial richness also was associated with a lower accumulation of chemical elements in the cellulose-based pellicle film, produced by survived microbiota in the post-test experiments, as compared to untreated cultures populated the film.

Keywords: Biology and Mars Experiments (BIOMEX), kombucha, biosignature, biofilm, bacterial cellulose. 


\section{Introduction}

Within the last decade, the European Space Agency (ESA) initiated a series of space biology exposure experiments exploiting multi-user exposure facilities - EXPOSE installed on the International Space Station (ISS) and BIOPAN on the retrievable satellite Foton. The general motivation was to perform a multi-purpose assessment of earthly (micro)organisms in the open space environment. These platforms allowed testing the impact of space-flight factors (vacuum, cycling temperature drops, cosmic radiation) and their combinations on earthly organisms. EXPOSE facilities allowed long exposures to space conditions and solar radiation outboard of the ISS to carry out different astrobiological experiments (Rabbow et al., 2012; 2015). Returning expose experiments on BIOPAN and EXPOSE-E facilities showed remarkable survival of several organisms used in the experiments, e.g., lichens and both prokaryotic and eukaryotic phototrophs (Cockell et al., 2011; Brandt et al., 2015). The next platform, EXPOSE-R2, was installed outside of the ISS to provide environment for four different sets of experiments available from July 2014 to February 2016.

A number of molecular and biochemical markers of viability of different forms of living organisms including microorganisms, spores and extracellular membrane vesicles (known as protocell nanoglobules), which potentially could serve as 'seeds' of life in the universe, have been proposed (Cohn, 1876; Arhenius, 1903; de Gregorio et al., 2013; Chen and Walde, 2010; Floss et al., 2014; Saha et al., 2014; Gill and Forterre, 2016). In the framework of the multipurpose international project "BIOlogical and Mars Experiment (BIOMEX)", a variety of organo-mineral samples were integrated into the EXPOSE-R2 platform to study vitality of pro- and eukaryotic organisms and stability of organic biomolecules as putative biomarkers (de Vera et al., 2012). The definition of biomarkers may vary in the context of different disciplines, but this should include molecules or compounds of the biological origin, which can be traced down by technical or scientific instruments to indicate life associated activities (Lovelock, 1965; Georgiou et al., 2014; Aerts et al., 2014).

Microbial cellulose has been identified as a significant extracellular matrix component of biofilms, which plays a key role in colonization of extreme environments by prokaryotes (Ross et al., 1991; Romling, Galperin, 2015). In the harsh environments, cellulose-forming bacteria can endure dry, cold, osmotic or heat stresses due to protective biofilms. Biofilm was defined as a structured microbial community enclosed in a self-produced polymer matrix to adhere the community to surfaces and spread in eco-niches (Costerton et al., 1999). The capability to synthesize cellulose has been documented in a wide variety of bacteria, including cyanobacteria, which occupy practically all eco-niches in the nature (see rev. Romling and Galperin, 2015) and in artificial confined niches (Hu et al., 2015). Being produced as early as 3.0-3.5 billion years ago (Nobles et al., 2001), cellulose can be considered as one of the most abundant polymer in the nature (Ross et al., 1991). In our previous studies, microbial cellulose produced by kombucha microbial community (KMC) was substantiated as a possible biosignature of bacterial 
activity (Kukharenko et al., 2012; Zaets et al., 2014 ). During the preparatory stage of the space-flight experiment BIOMEX, a series of ground-based tests (Experimental and Scientific Verification Tests, EVTs, SVT) was performed, which worked out the optimal scenario of development of organo-mineral specimens and methods of post-flight analyses of the pellicle microbiota and cellulose structural integrity. Desiccated and partly mineralized, but alive cellulose-based pellicle films comprising multi-component pro- and eukaryotic microbial assemblages resided in a latent form, were used in pre-flight tests.

\section{Materials and Methods}

\subsection{Microorganisms}

The kombucha microbial culture (KMC) Medusomyces gisevii Lindau IMBG 1 was obtained from the collection of microorganisms of the Institute of Molecular Biology and Genetics (Kyiv, Ukraine). It was maintained in a filter sterilized black tea (Camellia sinensis) (Lipton, 1.2\%, w/v) with white sugar $(3 \%, \mathrm{w} / \mathrm{v})(\mathrm{BTS})$ at $28^{0} \mathrm{C}$.

\section{2. Cultural media and cultivation conditions}

Nutrient media A, LB (Miller, 1972) and HS (Hestrin and Schramm, 1954) were used for bacterial growth and for yeast culturing, Glucose Yeast Peptone medium (HiMedia Laboratories, India) was used. Antibiotics cyclohexymide (100 $\mu \mathrm{g} / \mathrm{ml}$, Sigma-Aldrich) against yeasts and cephtriaxon (50 $\mu \mathrm{g} / \mathrm{ml}$, Roche Biochemicals) against bacteria were applied to avoid culture contamination. Identification of isolated bacteria and yeasts was based on morphological and cultural characteristics, and then proven by PCR and sequencing of amplified genetic markers (see below).

\subsection{Geological samples}

Anorthosite rock samples were obtained from the Penizevitchi deposit (Ukraine) (Mytrokhyn et al., 2003). Rocks were fragmented in particles of $0.1-1 \mathrm{~mm}$, sterilized by autoclaving at $120{ }^{0} \mathrm{C}$ for $40 \mathrm{~min}$, and then added to $\mathrm{KMC}$ culture as an additive $(20.0 \%)$.

\subsection{Bio-mineral sample preparation}

\subsubsection{Experiment Verification Test (EVT)-1}

For EVT-1, aliquots of sterile powder of anorthosite were mixed in sterile mortar with sterile dry egg white powder in proportion 1:1. All steps in this section were performed under aseptic conditions. The mixture was homogenized by stirring in the mortar. KMC samples grown in BTS for 7 days under $28^{\circ} \mathrm{C}$ were pelleted $\left(5,000 \mathrm{~g} 2 \mathrm{~min},+4{ }^{\circ} \mathrm{C}\right)$. The pellets were stirred with the mixture of rock and egg white powder (1:10) followed by adding minced pellicle. With a sterile spatula the mixture was filled into the holes of the sterile (autoclavation) device for tablet fabrication constructed for this study (Fig.S1.A). $\mathrm{KMC}$ samples in the form of tablets were collected in sterile Petri dish and kept at $28{ }^{0} \mathrm{C}$ for $1-2$ days to 
get it dry (Fig.S1.B). For the repeated experiment on EVT-1, KMC was grown in BTS supplemented with the anorthosite powder $(20 \% \mathrm{v} / \mathrm{v})$ in stationary conditions, and the 7 day-old KMC pellicle fragments were mixed with the anorthosite and egg white mixture.

\subsubsection{Experiment Verification Test 2}

KMC was grown in BTS supplemented with the anorthosite powder $(20 \% \mathrm{v} / \mathrm{v})$ in stationary conditions, and the 21 day-old KMC pellicle fragments were mixed with the anorthosite-egg white mixture to have it inside of the mineral samples.

\subsubsection{Science Verification Tests}

KMC was grown in BTS supplemented with the anorthosite powder $(20 \% \mathrm{v} / \mathrm{v})$. The 21 day-old KMC biofilm fragments $(\mathrm{d}=7 \mathrm{~mm})$ were built inside the organo-mineral mixture as it was described above. Samples were delivered to Cologne by fast post and accommodated in 16 well aluminium sample carriers with flat lower surfaces provided by DLR.

\subsection{Isolation of microorganisms from bio-mineral samples}

The tablets were placed into $5 \mathrm{ml}$ of sterile sugared tea infusion (BTS) and kept overnight; the next day it was minced and samples were inoculated into BTS and incubated for 30 days under stationary conditions as for KMC culturing mentioned above. Aliquots of the culture were plated on the selective agar media with appropriate antibiotics for bacterial or fungal growth (see p. 2.2).

\subsection{Isolation of cultivable forms of KMC-members entrapped in the cellulose-based biofilm}

For isolation of microorganisms, $1 \mathrm{~g}$ samples of wet KMC pellicle were homogenized in a sterile mortar with $0.2 \mathrm{ml}$ of $0.9 \% \mathrm{NaCl}$. The homogenate was serially diluted in the same solution and spread on selective media as mentioned in. 2.5 .

\subsection{Species identification}

The cultivable kombucha community members were identified by morphological features and proved by sequencing and analysis of the PCR products of marker genes (16S rRNA for bacteria and 26S for yeasts) as described previously (Reva et al., 2015).

\subsection{Randomly Amplified Polymorphic DNA Fingerprinting}

Total DNA samples from treated and untreated organo-mineral specimens were isolated using innuSPEED Bacteria / Fungi DNA isolation kit (Analytik Jena AG). The nucleic acids were quantified and qualified by a NanoDrop ND-1000 spectrophotometer (NanoDrop Technologies, Wilmington, DE). Two RAPD primers: OPO10 (5'-TCAGAGCGCC-3') for proteobacteria (Lee at al., 2012) and OPX-03 (5'-TGGCGCAGTG-3') for yeasts (Echeverrigaray at al., 2000) were chosen for amplifying kombucha microbial DNA in the experiment as it provided reproducible and discriminatory banding patterns. The 
PCR mixture consisted of a 100 ng microbial genomic DNA, $2.0 \mu 1$ 10x PCR buffer with $20 \mathrm{mM} \mathrm{MgCl}_{2}$, $2.0 \mu 110 \mathrm{mM}$ dNTPs, $1 \mathrm{U}$ Taq polymerase, 20 pM RAPD primer, and sterile ultrapure water was added to a final volume of $20 \mu \mathrm{l}$. The reaction was run for 40 cycles in the following condition: denaturation at $94{ }^{\circ} \mathrm{C}$ for $1 \mathrm{~min}$, annealing at $36{ }^{\circ} \mathrm{C}$ for $1 \mathrm{~min}$, and extension at $72{ }^{\circ} \mathrm{C}$ for $1 \mathrm{~min}$. An initial denaturation for $4 \mathrm{~min}$ at $95{ }^{\circ} \mathrm{C}$ and a final $7 \mathrm{~min}$ extension at $72{ }^{\circ} \mathrm{C}$ were applied. Products of the amplifications were resolved on $2.5 \%$ agarose gel, stained with ethidium bromide, and visualized under UV light. The gels were photographed and analyzed using PyElph 1.4 program. RAPD patterns were clustered using the unweighted pair-group method with arithmetic average (UPGMA).

\subsection{Biofilm microscopic analysis}

\subsubsection{Confocal Scanning Laser Microscopy (CSLM)}

Samples were fixed in the formaldehyde vapour during an hour and stained with calcofluor (excitation $405 \mathrm{~nm}$, filter BP 420-480), ethidium bromide (Sigma, USA) (excitation $514 \mathrm{~nm}$, filter BP $530-600 \mathrm{~nm}$ ), and thiazine dyes (excitation $514 \mathrm{~nm}$, filter BP 530-600 nm). A microscopic examination of sample fluorescence was performed, using CSLM AXIOSKOP - 2 ZEISS equipped by the LSM 510 PASCAL (CarlZeiss, FRG) software.

\subsubsection{Scanned Electron Microscopy/Energy-Dispersive X-ray Spectra (SEM/EDXS) microanalysis}

Scanned electron microscope Tescan Mira 3 LMU (Tescan s.r.o., Czech Republic) equipped with energy dispersive spectrometer (EDS/EDX) Oxford X-max 80mm (Oxford Instrument, UK) controlled by Inca Energy analysis software was used to provide chemical elemental analysis. Samples of the studied biofilm $(5 \times 5 \mathrm{~mm})$ were placed on specimen mount and dried in microscope under low pressure.

\subsection{Fourier Transform InfraRed (FT-IR) spectroscopy}

Infrared Fourier spectroscopy was used for the assessment of structural differences in natural and encrusted cellulose-based matrices. Each cellulose sample was air-dried on a glass slide in the form of a thin film. The film thickness was $0.025-0.03 \mathrm{~mm}$. The IR absorption analysis was carried out, using a Bruker-113v Fourier Transform spectrometer. The measurements were performed at room temperature in the range of $50-4000 \mathrm{~cm}^{-1}$ with a spectral resolution of $1.0 \mathrm{~cm}^{-1}$.

\subsection{Tests facilities and exposure conditions}

\subsubsection{Experiment Verification Tests procedure}

Two ground-based pre-flight EVTs aimed to simulate space-flight, and partially Martian conditions at EXPOSE-R2 platform outside the ISS (EVT-1 and EVT-2), were performed, using the Planetary and Space Simulation facilities at the Institute of Aerospace Medicine (German Aerospace Center, DLR, Cologne, Germany). Bio-mineral samples were exposed to the following conditions: vacuum $\left(10^{-5} \mathrm{~Pa}\right.$, as 
expected to prevail during the space flight, 7 days), temperature fluctuations $\left(-25 /+60{ }^{\circ} \mathrm{C}\right)$, temperature cycling (66 cycles $8 \mathrm{~h}$ each, $2 \mathrm{~h}$ at $-10^{\circ} \mathrm{C} \pm 1{ }^{\circ} \mathrm{C}, 2 \mathrm{~h}$ at $+45^{\circ} \mathrm{C} \pm 1{ }^{\circ} \mathrm{C}, 2 \mathrm{~h}$ each for cooling and heating). The temperature was monitored with a sensor attached to the inner side of the sample carrier. The SOL2000 was used without optical filters to emit polychromatic UV rays (installed at DLR Cologne, Germany). In EVT-1 the irradiation with monochromatic UVC (254 nm) was applied up to the final dose of $10 \mathrm{kJm}^{-2}$. Within the EVT-2, samples responded to enhanced polychromatic UV-radiation. For the polychromatic irradiation experiment, not exposed "dark" samples served as the control for the irradiation tests. Simulated Martian atmosphere $\left(\mathrm{CO}_{2}\right.$ gas composition, pressure $\left.10^{3} \mathrm{~Pa}\right)$ were used in the EVT and SVT-1, 2. All samples were used in triplicate. The exposure to simulated conditions in the EVT1 and EVT-2 was carried out by placing the samples in the carrier at appropriate positions. EVT-1and EVT-2 were performed twice.

\subsubsection{Science Verification Test hardware}

In the SVT, samples were arranged in 3 layers of flight-identical ground carriers (4 specimens in either one): in the top of the UV exposed layer, and dark positions in the medium and bottom layers of tray 2, as for a flight. The tray was attached to Planetary and Space Simulation Facility (PSI) 2 for addition of Mars gas at $10^{3} \mathrm{~Pa}$ (Fig.1.A, B, C).

The SVT exposure period started on December 10th, 2013 and lasted until January 14, 2014. A total UV fluence of $5.5 \times 10^{5} \mathrm{Jm}^{-2}$ for the biologically active wavelength range of 200-400 nm was applied, simulating a one year mission exposure. Irradiation was performed discontinuously, to allow a constant monitoring of the temperature and the cryostat function to avoid heating of the sample during the irradiation. Temperature was controlled by sensors attached to the tray 2 . Temperature of the tray structure never exceeded $10^{\circ} \mathrm{C}$ during irradiation. Between irradiations, samples were cooled to $-25^{\circ} \mathrm{C}$. Tray 2 was connected to the vacuum facility PSI 2 (Fig.1.C) and evacuated to $1.3 \times 10^{-3} \mathrm{~Pa}$. The PSI 2 recipient with the attached tray 2 was flooded with Mars-like gas composed of $95.55 \% \mathrm{CO}_{2}, 2.70 \% \mathrm{~N}_{2}, 1.60 \% \mathrm{Ar}$, $0.15 \% \mathrm{O}_{2}, \sim 370 \mathrm{ppm} \mathrm{H}_{2} \mathrm{O}$, provided by Praxair Deutschland $\mathrm{GmbH}$, to a final pressure of $10^{3} \mathrm{~Pa}$. The tray was disconnected from PSI 2 and accommodated on the temperature control interface.

Samples were glued as for the flight (space approved non-outgassing glue Wacker-silicone RTV-S $691 \mathrm{~A}+\mathrm{B}$, prepared from the two components according to the manufacturers manual) and integrated under sterile conditions into the appropriate sample carriers at their positions.

\subsection{Statistical tests}

The significance of differences between means from three samples were based on Student's $t$-test ( $p$ $<0.05)$. 


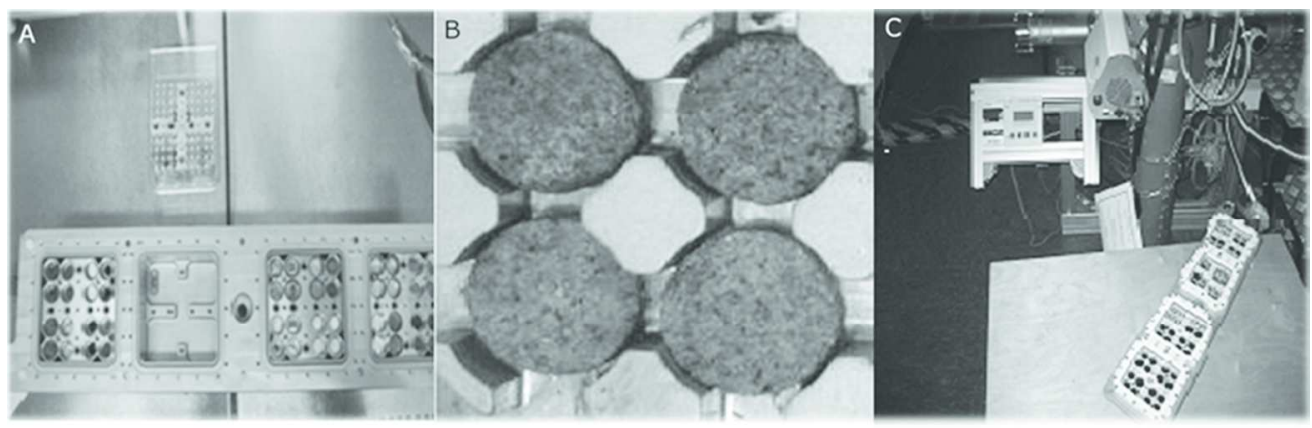

$85 \times 27 \mathrm{~mm}(300 \times 300 \mathrm{DPI})$

FIG. 1. Tray 2 integration of sample carriers and filter frames. Biomineral samples in a lower sample carrier (A); macroscopic image of samples (B); tray 2 attached to the PSI (C). Gas, simulating the martian atmosphere, was added to a final pressure of $10^{3} \mathrm{~Pa}$. (Credit: DLR) 


\section{Results}

\subsection{Pre-flight tests: influence of space-flight and Martian-like factors}

\subsubsection{Microbial community survival and biofilm formation}

For the EVT-1, bio-mineral samples were developed in a form of tablets under aseptic conditions, using pristine kombucha pellicle fragments and cell precipitates mixed with sterile anorthosite powder. For the EVT-2, mineralized pellicle has been used instead of pristine one. Table.S1 shows data on survival and biofilm formation by kombucha multimicrobial culture after irradiation in the frame of the EVT-1 and EVT-2 (run 1) tests after a week and a month period of cultivation of treated and control specimens.

In the first pre-flight experiment EVT-1 performed at the pressure simulating Mars atmosphere, and as well in vacuum $\left(10^{-5} \mathrm{~Pa}\right)$, biofilm-producing microbes survived and produced thin cellulose-based pellicles in contrast to the laboratory control culture, producing a more rigid pellicle (Fig.2A). Short wavelength UVC radiation was used in the pre-flight test programs. Four fluences $\left(8,000-10,000 \mathrm{~J} / \mathrm{m}^{2}\right)$ of monochromatic UVC were provided for the evaluation of the dose-effect response of the bio-mineral samples. After the UV-doses of 1,000-10,000 J/m² irradiated KMC variants exhibited lysis, in contrast to laboratory and transportation controls (Fig.2B). Nevertheless, the lysed cultures recovered within a week and produced new pellicle. In the EVT-1, run 2, mineralized biofilm fragments have been used, and no culture lysis occurred; however, a delayed recover of cellulose-forming bacterial strains has been reported. The polychromatic irradiation used simulates terrestrial UV spectrum without the ozone layer, but with the absorption of the terrestrial atmosphere. It was applied as the most deleterious space factor, influencing deadly most biological samples. KMC retained at this condition the cellulose producing capacity up to $14,000 \mathrm{~J} / \mathrm{m}^{2}$ dose during $3 \mathrm{~h}$, although the production of the cellulose decreased under the impact of this stressor. Under two higher irradiations with fluences, simulating the possible mission durations of 12 months with $5 \times 10^{5} \mathrm{~J} / \mathrm{m}^{2}$ and 18 months with $8 \times 10^{5} \mathrm{~J} / \mathrm{m}^{2}$, neither bacterial nor fungal members of the cellulose-forming community did not germinate within 30 days. However, Bacillus sp. have been recovered from samples irradiated with these high UV doses.

\subsection{Pre-flight EXPOSE-R2 SVT tests: the cumulative effect of simulated stressful factors}

For the SVT exposure, bio-mineral samples were modified as mentioned above and prepared according to the new protocol. In addition to survival and biofilm formation tests, structural integrity of both bacterial cellulose (BC) and the total community DNA after exposing to the stressful factors were tested.

After the flight transportation from Kyiv to Cologne, the specimens were in good shape and were glued into the sample wells of all 3 layers of the tray 2. Accommodated in the tray, samples were exposed 


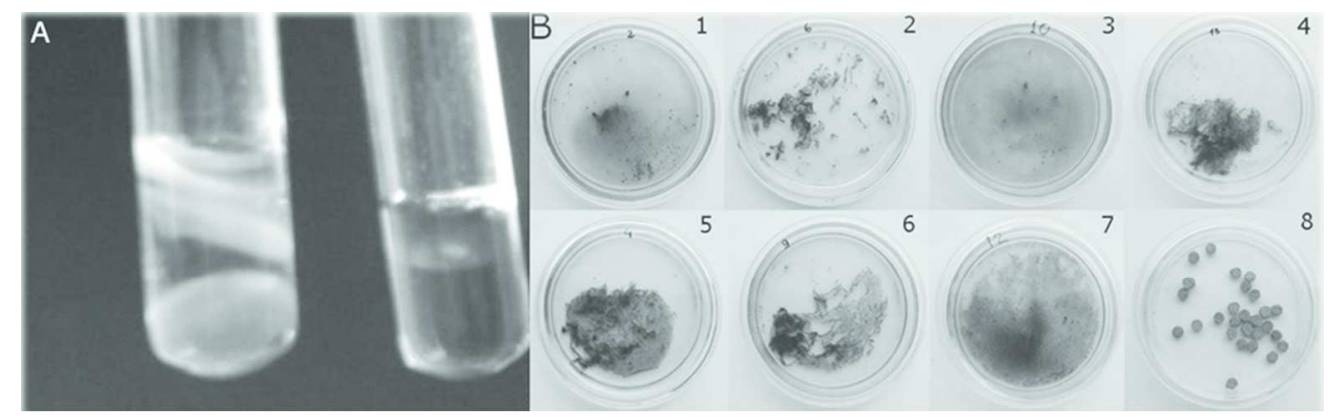

$85 \times 26 \mathrm{~mm}(300 \times 300 \mathrm{DPI})$

FIG. 2. Post-treatment experiments on recovery of kombucha microbial culture from biomineral samples. (A) Biofilm-producing microbes that survived in the simulated martian atmosphere; after revival, kombucha microbial culture retained its cellulose-producing capacity, although the production of cellulose decreased (left: a control, untreated culture; right: the tested kombucha culture, in vials). (B) A view of a 21-day kombucha microbial culture grown in Petri dishes after a treatment with different spacelike factors (1: a Mars-like atmosphere; 2, 4-7: UV irradiation of doses $10,000,1,500,1,000,100$, and $8 \mathrm{~J} / \mathrm{m}^{2}$ ) during the preflight EVT-1 as compared to a laboratory control culture (3). Biomineral samples, consisting of anorthosite and the pristine kombucha biofilm fragments (8), were tested, using the Planetary and Space Simulation facilities at the Institute of Aerospace Medicine (DLR, Cologne, Germany). 
to Mars-like conditions, i.e., in a Mars gas mixture at reduced pressure conditions of $10^{3} \mathrm{~Pa}$ and to UV wavelengths $>200 \mathrm{~nm}$, as expected on Mars.

\subsubsection{Microbial organisms survival and biofilm forming}

After the SVT exposure, specimens from a top layer did not exhibit visible bacterial growth in nutrient media after one month incubation. However, analogous specimens (from the middle and bottom layers), which were protected from UV radiation by the top layer, showed that in Mars-like atmosphere and pressure the minimal components of kombucha community had survived - Komagateibacter spp., Pichia sp., Zigosaccharomyces bailii, however, Dekkera anomala and Gluconobacter oxydans were not observed despite being the major KMC members at normal conditions. In the samples from both the bottom and medium layers, the cellulose-forming bacteria showed ability to produce biofilm after the community revival within 5 weeks. In contrast, the laboratory and transportation control samples produced the film within 7 days.

\subsubsection{SEM/EDX-ray spectra microanalysis of the BC-based membranes after SVT}

In our previous study, we showed that pristine pellicle BC-based membranes included several chemical elements originated from tap water also extracted from tea leaves and sugar used in the nutrition medium composition (Zaets et al., 2014). In presence of anorthosite rock, KMC-members bioleached inorganic ions and accumulated them at a higher extent on the bottom side of the pellicle film than KMC grown without anorthosite. In this study, a number of detected elements in films accumulated by bacteria survived after SVT-related stressors within tray 2 (middle and bottom layers) was unexpectedly low, comparing to native film (FIG.3.A1,2). Except organogenic $\mathrm{C}$ and $\mathrm{O}$ elements, $\mathrm{Ca}$ and $\mathrm{K}$ were detected, while the EDX-ray spectra of films produced by untreated KMC uncovered $\mathrm{Ca}, \mathrm{Al}, \mathrm{Si}$, K, Cl (FIG.3.B1,2).

\subsubsection{Molecular characterization of total KMC DNA by the RAPD fingerprinting method}

The DNA specimen isolated from the dry laboratory control sample (Tc) reproduced the same RAPD/PCR DNA band patterns, as in the sample isolated from live KMC originated from the Tc sample did. However, visible differences were detected between RAPD/PCR patterns of DNA bands from laboratory dry sample and the samples from the middle-layer $(\mathrm{Tm})$ and top $(\mathrm{Tt})$ carriers for both bacterial and yeast populations (Fig.4.A,B).

\subsubsection{CLSM analysis of biofilms}

After the SVT, the restored from organo-mineral specimens (the middle-layer tablets) kombucha culture produced mineral grains (ø $0.09-0.025 \mathrm{~mm}$ ), which were observed in the bottom side of the encrusted cellulose-based film (Fig.5A,B). Parental culture also produced mineral grains in the presence of anorthosite (Fig.5C), however, the average size of formed grains were smaller (ø $0.02-0.01 \mathrm{~mm})$. 
A
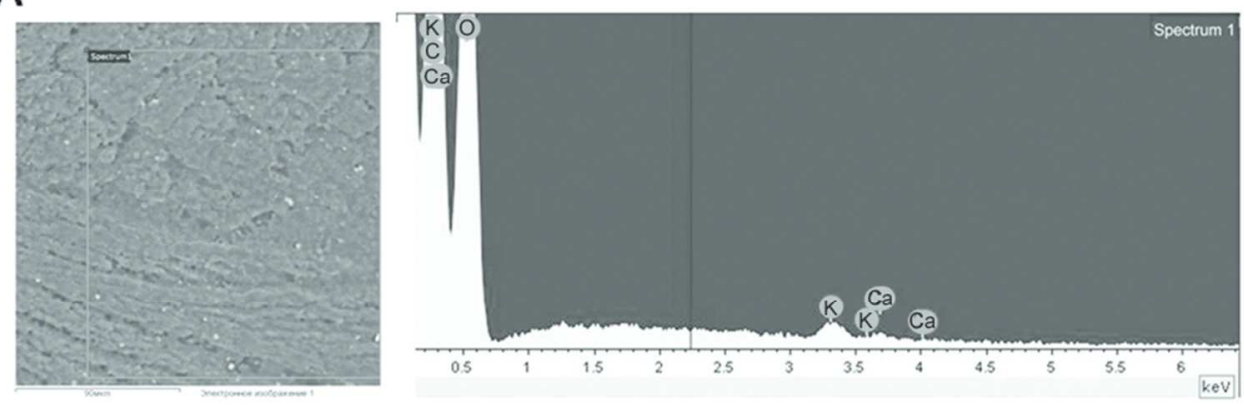

$85 \times 29 \mathrm{~mm}(300 \times 300$ DPI $)$ 


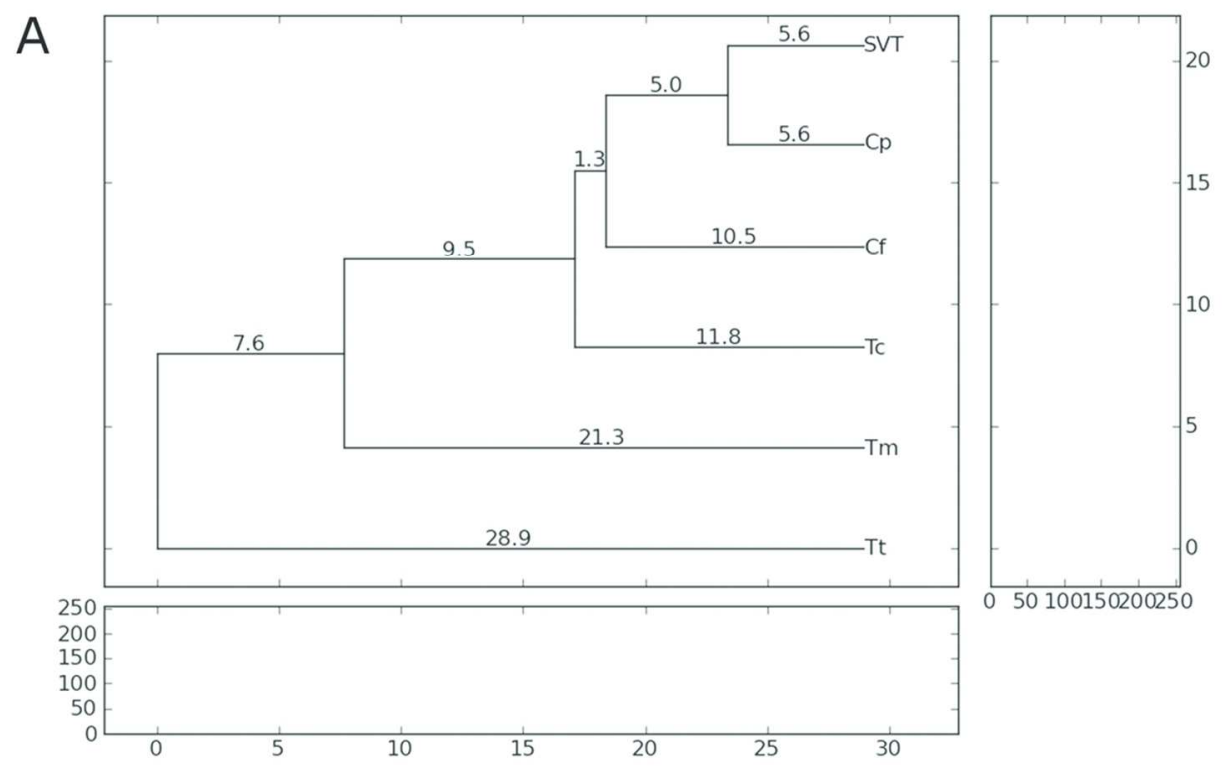

$50 \times 30 \mathrm{~mm}(600 \times 600$ DPI $)$ 


\section{B}
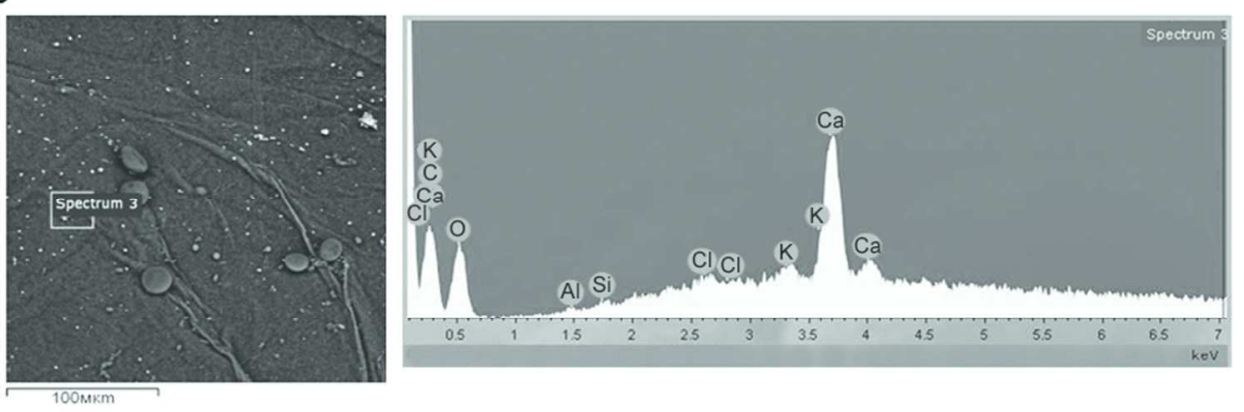

$85 \times 31 \mathrm{~mm}(300 \times 300$ DPI)

FIG. 3. Scanning electron micrographs (left) and energy-dispersive Xray spectra (right) of the cellulose-based pellicle film produced by survived cellulose-forming bacteria after the impact of space- and Marsrelated stressors in SVT (total UV fluence was $5.5 \cdot 10^{5} \mathrm{~J} / \mathrm{m}^{2}$ for 200-400 $\mathrm{nm}$; Mars gas at $\left.10^{3} \mathrm{~Pa}\right)(\mathrm{A})$ and by pristine kombucha culture (B). 


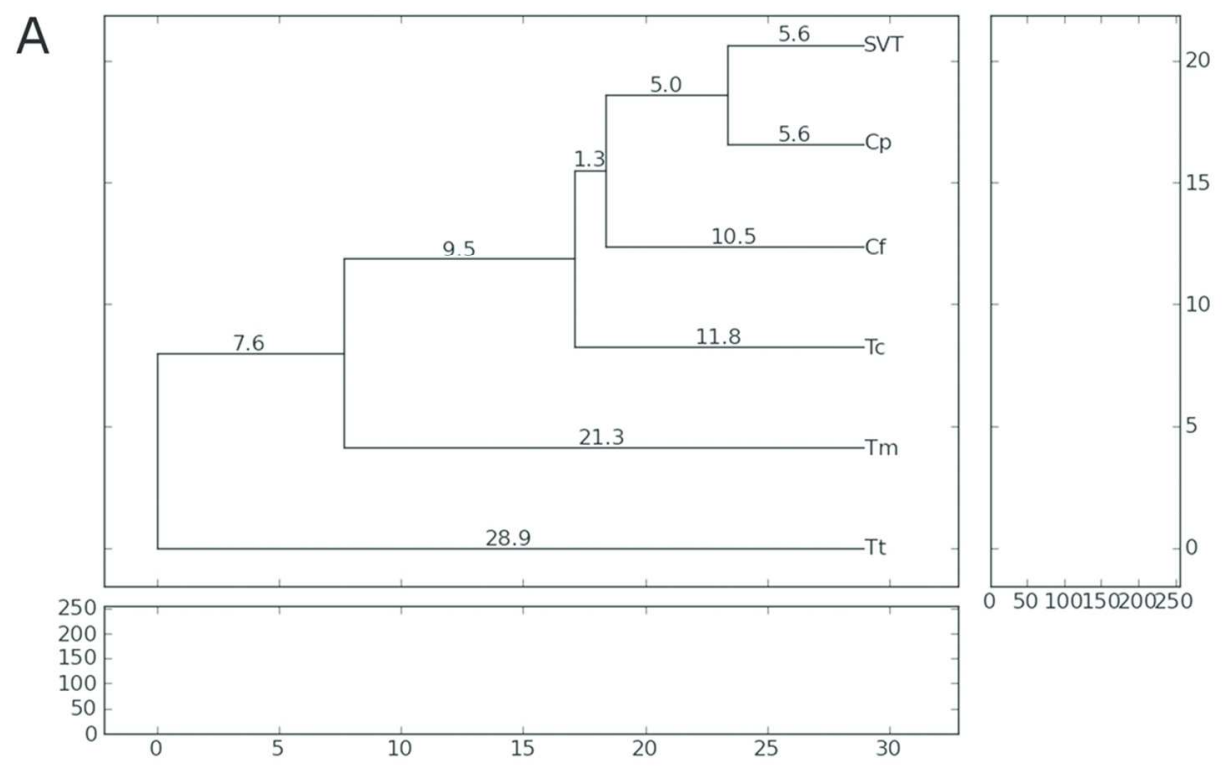

$50 \times 30 \mathrm{~mm}(600 \times 600$ DPI $)$ 


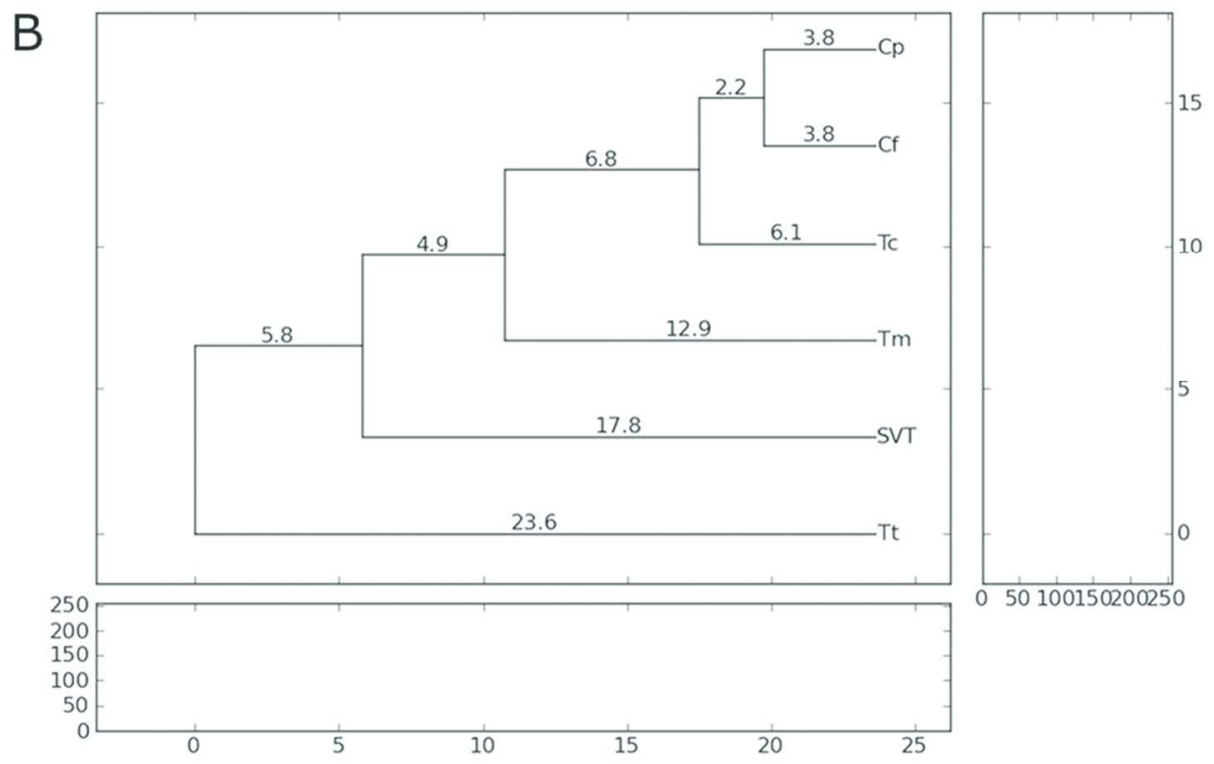

$50 \times 30 \mathrm{~mm}(600 \times 600 \mathrm{DPI})$

FIG. 4. Cluster analysis of the proteobacterial (A) and yeast (B) communities' RAPD/PCR band patterns, using the UPGMA clustering method. Control samples: Tc, a dry control sample; Cf, a revived control (biofilm); Cp, a revived control (precipitate). SVT samples: Tt, a dry sample from a top layer; Tm, a dry sample from a medium layer; SVT, a revived sample that originated from a bottom carrier (biofilm). 

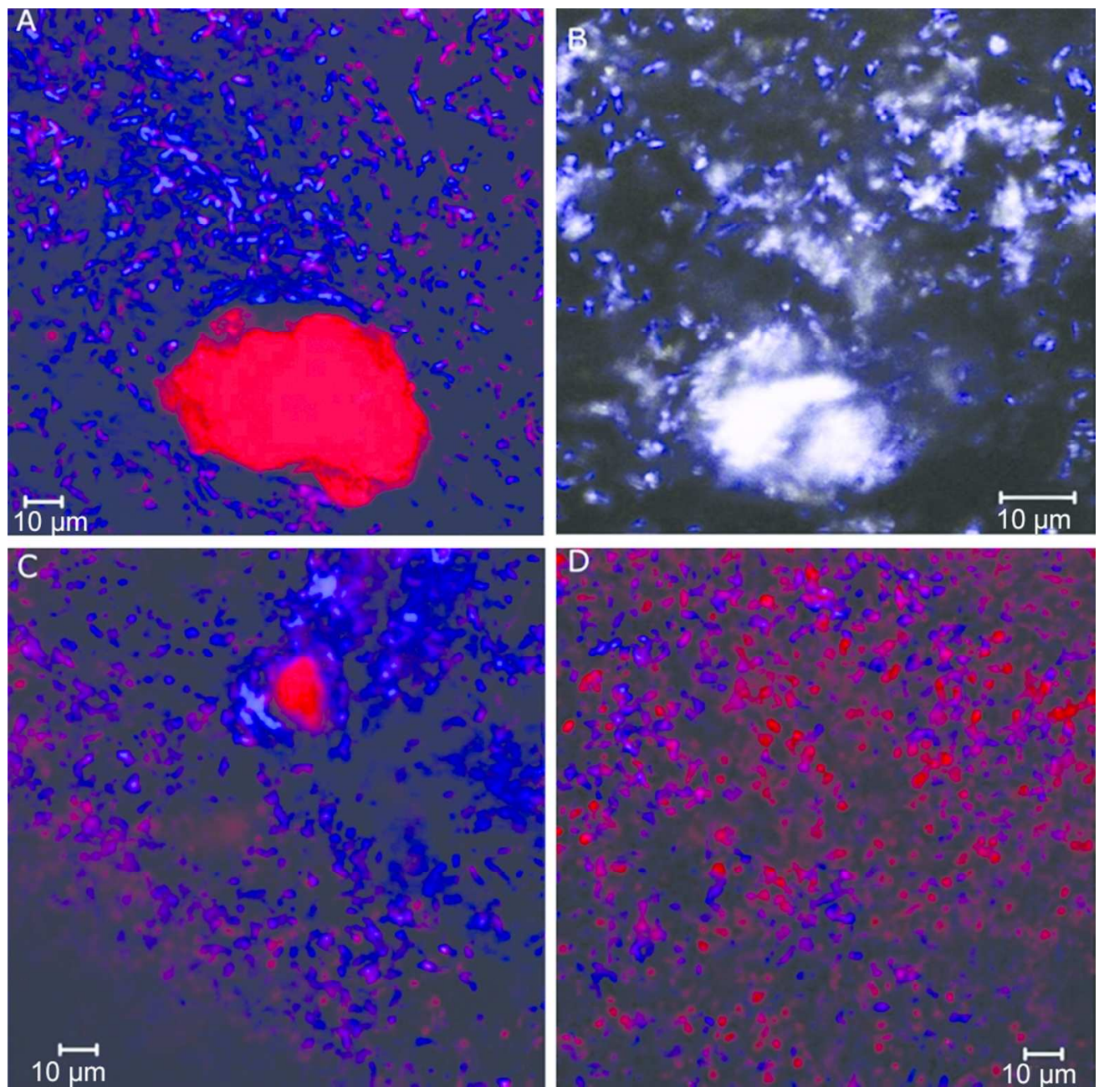

$85 \times 84 \mathrm{~mm}(300 \times 300$ DPI $)$

FIG. 5. Confocal scanning laser micrographs of the mineralized cellulose biofilm produced by kombucha culture in the presence of anorthosite. (A) Micrograph of the bottom side of encrusted cellulose biofilm produced by the kombucha culture, being restored after SVT (total UV fluence was $5.5 \cdot 10^{5} \mathrm{~J} / \mathrm{m}^{2}$ for $200-400 \mathrm{~nm}$; Mars gas at $10^{3} \mathrm{~Pa}$ ). The source of anorthosite was a rock material that served as a carrier for biomaterial. Nucleic acids stained with ethidium bromide (red signal), cellulose stained with calcofluor with blue excitation. (B) Micrograph of the bottom side of encrusted cellulose biofilm, produced by the kombucha culture restored after SVT. Nucleic acids stained with Hoechst (blue signal). (C) Micrograph of the bottom side of encrusted cellulose biofilm, produced by the typical kombucha culture in the presence of anorthosite in the medium under normal conditions. In (A)-(C), mineral grains were heavily colonized by microbial organisms. (D) Control cellulose-based bottom side pellicle without visible mineral depositions. Cellulose stained with calcofluor with blue excitation, nucleic acids stained with ethidium bromide (red signal). Scale bars equal to $10 \mathrm{~mm}$. 
Control cellulose-based pellicle grown in the absence of anorthosite was without visible mineral depositions (Fig.5D).

On the bottom side of the pellicle produced by KMC after SVT (the middle-layer pills), microbial landscape differed from the latter one in control pellicles by morphology and the cell number (Fig.5.A,D). This may serve as an additional evidence that some changes have happened in the structure of KMC, in which also influenced the evenness of the community-members after the impact of SVT factors, i.a., vacuum, temperature cycles, and Mars atmosphere \& pressure.

\subsubsection{FT-IR spectroscopy of mineralized bacterial cellulose after SVT}

The IR spectra of the cellulose biofilm matrix samples were taken in order to detect changes that could be attributed to the impact of simulated Martian conditions on the BC structure. Fig.6a shows the absorption spectra of BC-based matrix produced by the kombucha culture restored after the SVT. By FTIR spectroscopy, the BC from bio-mineral samples (the middle-layer tablets) was found to be indistinguishable from the cellulose produced in the presence of anorthosite (Fig.6b). The treated KMC produced cellulose, which preserved spectral feature characteristics (e.g., $960-730 \mathrm{~cm}^{-1}$, the fingerprint region of anomeric carbons, wherein a band at $897 \mathrm{~cm}^{-1}$ confirmed the presence of $\beta-1,4-$ linkages specific for cellulose polymer). However, several spectral differences were observed between mineralized (Fig.6b) and native cellulose (Fig.6c) as resulted most likely from accumulation of metals bioleached from the rock in the cellulose matrix (Zaets et al., 2014).

\section{Discussion}

The focus of this study was to prove the idea of stability of bacterial cellulose as putative biosignature under pre-flight simulated conditions. This mini-project consisted of few successive phases, from the idea (Kukharenko et al., 2012) and laboratory preparatory research (Zaets et al., 2014; Reva et al., 2015; Kharina et al., 2015; Podolich et al., 2016) to the multistep simulation experiments, using PSI2 (DLR, Cologne). For the pre-flight ground experiments, the multi-microbial cellulose-based KMC pellicle films were embedded in the rock material to test, first of all, the integrity of bacterial cellulose polymer in Mars-like $\mathrm{CO}_{2}$-atmosphere under solar radiation that mimics the solar spectrum on the surface of Mars. Whereas the structural integrity of cellulose polymer examined with FT-IR spectroscopy was not disturbed by experimental conditions, the survival capacity of the KMC-members depended on exposure conditions within experimental tray, as well as on the method of specimen preparation.

\subsection{Links between stress responses and cellulose structural integrity}

The mineralization of pellicle biofilm has been recorded in changed cellulose IR-spectra; for instance, a bell-like peak in the region corresponding to $-\mathrm{OH}$ stretching could indicate that $-\mathrm{OH}$ groups were engaged in $\mathrm{BC}$ interaction with inorganic ions and in formation of complexes with metals.However, 


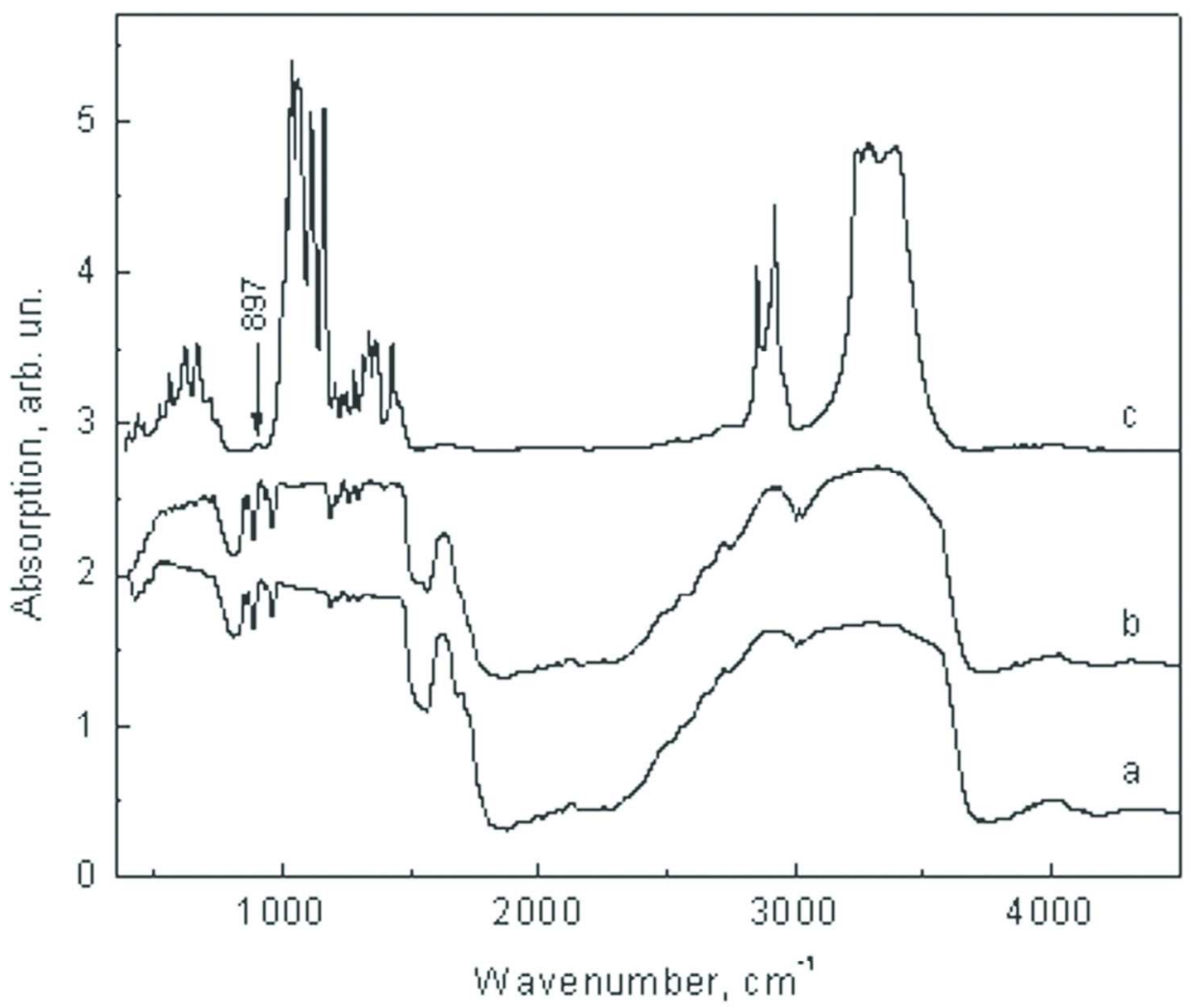

$74 \times 65 \mathrm{~mm}(600 \times 600$ DPI $)$

FIG. 6. The IR absorption spectra of a biofilm produced by kombucha culture that was restored after the SVT ex-posure (a total UV fluence of $5.5 \cdot 10^{5} \mathrm{~J} / \mathrm{m}^{2}$ for $200-400 \mathrm{~nm}$; Mars gas at $10^{3} \mathrm{~Pa}$ ) (a), a biofilm formed in the presence of anorthosite (b), and a BC-based natural biofilm (c) in the range of $400-4000 \mathrm{~cm}^{-1}$. The spectra are shifted on the vertical axis for clarity. The band at $897 \mathrm{~cm}^{-1}$ confirms the presence of $\beta$-1,4-linkages in the molecule of cellulose. 
the bacterial cellulose molecular identity could be confirmed by IR-spectroscopy. After a treatment of bio-mineral samples, IR-spectra were found to be the same as those obtained from the cellulose produced in presence of anorthosite. Also the treated KMC produced cellulose, which preserved spectral feature characteristics, e.g, the $960-730 \mathrm{~cm}^{-1}$ fingerprint region of anomeric carbons, wherein a band at $897 \mathrm{~cm}^{-}$

${ }^{1}$ confirmed the presence of $\beta$-1,4-linkages specific for cellulose polymer. These data demonstrate high stability of the cellulose molecule and prove our idea to consider this polymer as a biomarker of live matter.

\subsection{Links between stress responses and the structure of $K M C$}

More diverse communities are less affected by perturbations than less diverse ones (Zaets, 2009; Awasthi et al., 2014), and this was a leading criterion for decision-making regarding selection of the KMC model as an alternative model based on a biofilm-producing monoculture. In the preparatory study, the information on the KMC structure was obtained using cultural and culture-independent (DNAmetabarcoding) approaches. It was shown that KMC consisted of several bacterial and yeast species, some of which were uncultivable and unknown (Ovcharenko et al., 2013; Reva et al., 2015). Besides, it was shown that the naturally selected core kombucha culture composition was stable under different growth conditions and could represent the population under non-optimal conditions (Reva et al., 2015; Podolich et al., 2016). In this study, the minor limiting factor for the community-members was anorthosite, i.a., the excess of biomobilized inorganic ions derived from this rock material, which could be a reason for the observed reduction of the community-members. In simulations mimicking Mars-like atmosphere and pressure, the cellulose-producing bacteria Komagateibacter spp. survived these conditions and produced cellulose-based pellicles after re-cultivation. Earlier, Kato et al. (2007) showed that Komagataeibacter sp. possessed a barotolerant feature - ability to survive at $100 \mathrm{MPa}$ pressure, which corresponded to the deep sea at $10,000 \mathrm{~m}$.

After impact of different simulated space-flight and Martian factors on KMC, changes in the KMC structure were seen as a consequence of their synergistic effect influenced samples within the bottom and middle carriers in the SVT program. Yeast species D. anomala and bacterial species G. oxydans were not found in the treated bio-mineral specimens. Microbiological data were proven by RAPD/PCR and provided evidence that $\mathrm{KMC}$ undergone adaptive changes in response to dysregulated mineral metabolism.

A set of fluences used in the SVT treatments was harmful for specimens located in the top layer. Both microbiological and molecular analysis showed that microbial organisms exposed in the top samples more likely were killed or entered VBNC (the viable but nonculturable) state as there was no growth on nutrition medium and their DNA was partially degraded. The major limiting factor for the communitymembers survival was the UV irradiation damaging cells and destroying the community. In analogous tests, Baqué et al. (2013) showed that biofilms of desert cyanobacterium Chroococcidiopsis tolerated UV 
polychromatic radiation combined with simulated space vacuum or Martian atmosphere in EVT, and Meeßen et al. (2015) revealed lichens Buellia frigida was capable of surviving the conditions tested in EVT and SVT, in frames of the BIOMEX pre-flight tests.

The tests on the high-dose-UV irradiation, using PSI in DLR (Cologne) showed that neither the dehydrated cellulose matrix nor the layer of anorthosite above the pellicle in organo-mineral samples could shield and protect cellulose-forming bacteria from UV-doses higher $10 \mathrm{~kJ} / \mathrm{m}^{2}$. However, several KMC members, although dormant and uncultivable, managed to survive these harsh conditions, e.g., Gram-positive Bacillus sp. which tolerated up to $10 \mathrm{~kJ} / \mathrm{m}^{2}$ dose. Metabarcoding of KMC showed presence of Bacillus sp. even that they had never been isolated in pure culture (Reva et al., 2015). Ability of Bacillus to withstand extreme conditions is well known. For example, the soil isolate B. pumilus showed resistance to $100 \mathrm{~kJ} / \mathrm{m}^{2} \mathrm{UV}$ dose (Gabani et al., 2012). Selection under the influence of the stressors could activate unculturable population of Bacillus sp. in post-irradiation experiments. Here, we once more showed that the structure of polymicrobial kombucha culture depended on exposure conditions, and non-optimal ones either eliminated some of community-members or resuscitated the uncultivable latent forms.

4.3. Link between the structure of KMC and accumulation of elements within the cellulose-based film

The changes of the KMC structure in specimens from the middle and bottom layers correlated with data of the elemental analyses of cellulose-based films produced by survived bacteria and other inhabiting community-members in post-treatment laboratory experiments. In particular, a range of detected elements in those films was unexpectedly narrow, comparing to native film. This may be explained by the reduced richness of community populations after the impact of stressors and appropriate reduction of total biomobilizing activity in KMC. In our previous study, the biomobilization of elements by KMC community-members and accumulation them in pellicle films were shown in the KMC biofilmanorthosite system, where anorthosite was separated from the cellulose-based film with cultural liquid (Zaets et al., 2014). In spite of anorthosite- and biofilm-phase separation, the film accumulated inorganic ions (mobilized from the rock by planktonic microbial cells) and became grey, in contrast to native biofilm produced by KMC without anorthosite. In this study, after pre-flight simulations, survived KMCmembers also exhibited biomobilization and accumulation capacity, however, restricted to few elements as compared to parental untreated KMC.

\section{Conclusion}

Dehydrated cellulose-based pellicle protects bacterial and yeast cells from adverse factors like a low-dose ultraviolet radiation $\left(<1,000 \mathrm{~J} / \mathrm{m}^{2}\right)$, temperature fluctuations, vacuum or Martian-like conditions. Under stressful conditions of a higher-dose of UV-irradiation $\left(1,000-10,000 \mathrm{~J} / \mathrm{m}^{2}\right)$ the KMC structure is 
unstable, however, the key players of KMC recover its capability to grow under optimal conditions both as planktonic cultures and within the cellulose web. Taking into account a slow revival of the community, the low-dose UV is defined as limiting factor, but not critical. Critical for the kombucha culture survival is a high dosage $\left(>10,000 \mathrm{~J} / \mathrm{m}^{2}\right) \mathrm{UV}$ irradiation. Pre-conditioned kombucha culture, previously grown in the presence of anorthosite, exhibits a better survival/revival capacity of the cellulose-forming bacteria. The mineralization of pellicle biofilm changes cellulose molecule, however, the bacterial cellulose preserves molecular identity, as confirmed by IR-spectroscopy.

\section{Acknowledgments}

This study was supported by National Academy of Sciences of Ukraine (grant 47/2012-15). The pre-flight programs EVTs and SVTs for the EXPOSE-R2 mission were supported by the European Space Agency.

\section{Author Disclosure Statement}

No competing financial interests existed.

\section{References}

Aerts, J.W, Röling, W.F.M., Elsaesser, A., Ehrenfreund, P. (2014) Biota and biomolecules in extreme environments on earth: implications for life detection on Mars. Life 4(4):535-565.

Arrhenius, S. (1903) Die Verbreitung des Lebens im Weltraum. Die Umschau 7:481-485.

Awasthi, A., Singh, M., Soni, S.K, Singh, R., Kalra, A. (2014) Biodiversity acts as insurance of productivity of bacterial communities under abiotic perturbations. The ISME Journal 1-8.

Baqué, M., Verseux, C., Böttger, U., Rabbow, E., de Vera J.-P., Billi, D. (2015) Preservation of biomarkers from Cyanobacteria mixed with Mars like regolith under Simulated Martian Atmosphere and UV flux. Orig Life Evol Biosph doi:10.1007/s11084-015-9467-9.

Brandt, A., de Vera, J.-P., Onofri, S., Ott, S. (2015) Viability of the lichen Xanthoria elegans and its symbionts after 18 months of space exposure and simulated Mars conditions on the ISS. International Journal of Astrobiology 14(3):411-425.

Chen, I.A., Walde, P. (2010) From self-assembled vesicles to protocells. Cold Spring Harb Perspect Biol. 2(7):a002170.

Cockell, C.S., Rettberg, P., Rabbow, E., Olsson-Francis, K. (2011) Exposure of phototrophs to 548 days in low Earth orbit: microbial selection pressures in outer space and on early earth. ISME J 1-12.

Cohn, F. (1876) Untersuchungenüber bacterien. IV. Beiträgezur biologie der Bacillen. In: Beiträgezur Biologie der Pflanzen 7:249-267.

Costerton, J.W., Stewart, P.S., Greenberg, E.P. (1999) Bacterial biofilms: a common cause of persistent infections. Science 284:1318-1322. 
de Gregorio, B.T., Stroud, R.M., Nittler, L.R., Alexander, C.M.Od., Bassim, N.D., Cody, G.D., Kilcoyne, A.L.D., Sandford, S.A., Milam, S.N., Nuevo, M., Zega, T.J. (2013) Isotopic and chemical variation of organic nanoglobules in primitive meteorites. Meteoritics \& Planetary Science 1-25.

de Vera, J.-P., Boettger, U., Schmitz, N., Lange, C., Hübers, H.-W., Jaumann, R., Spohn, T. (2012) Co-I team of BIOMEX. supporting Mars exploration: BIOMEX in low earth orbit and further astrobiological studies on the moon using raman and PanCam technology. Planetary Space Science 74(1):103-110.

Echeverrigaray, S., Paese-Toresan, S., Carrau, J.L. (2000) RAPD marker polymorphism among commercial winery yeast strains. World Journal of Microbiology and Biotechnology 16:143-146.

Floss, C., Guillou, C.L., Brearley, A. (2014) Coordinated NanoSIMS and FIB-TEM analyses of organic matter and associated matrix materials in CR3 chondrites. Geochimica et Cosmochimica Acta 139(15):1-25.

Gabani, P., Copeland, E., Chandel, A.K., Singh, O.V. (2012) Ultraviolet-radiation-resistant isolates revealed cellulose-degrading species of Cellulosimicrobium cellulans (UVP1) and Bacillus pumilus (UVP4). Biotechnol Appl Biochem 59(5):395-404.

Georgiou, C.D., Deame, D.W. (2014) Lipids as universal biomarkers of extraterrestrial life. Astrobiology 14(6):541-549.

Gill, S., Forterre, P. (2016) Origin of life: LUCA and extracellular membrane vesiscles (EMVs). Int $J$ Astrobiol 15(1):7-15.

Hestrin, S., Schramm, M. (1954) Synthesis of cellulose by Acetobacter xylinum. 2. Preparation of freeze-dried cells capable of polymerizing glucose to cellulose. Biochem $J$ 58:345-352.

Hu, L., Grim, C.J., Franco, A.A., Jarvis, K.G., Sathyamoorthy, V., Kothary, M.H., McCardell, B.A., Tall, B.D. (2015) Cronobacter species: Prevalence among species and their roles in biofilm formation and cell-cell aggregation. Food Microbiology 52:97-105.

Kato, N., Sato, T., Kato, S. et al. (2007) Viability and cellulose synthesizing ability of Gluconacetobacter xylinus cells under high-hydrostatic pressure. Extremophiles 11(5):693-698.

Kharina, A., Podolich, O., Faidiuk, I., Zaika, S., Haidak, A., Kukharenko, O., Zaets, I., Tovkach, F., Reva, O., Kremenskoy, M., Kozyrovska, N. (2015) Temperate bacteriophages collected by outer membrane vesicles in Komagataeibacter intermedius. J Basic Microbiol 55(4):509-513.

Kukharenko, O., Podolich, O., Rybitska, A., Reshetnyak, G., Burlak, L., Ovcharenko, L., Voznyuk, T., Moshynets, O., Rogutskyi, I., Zaets, I., Yaneva, O., Pidgorskiy, V., Rabbow, E., de Vera, J.-P., Kozyrovska, N. (2012) Robust symbiotic microbial communities in space research, in: Fedorov, O. P. (Ed), Space research in Ukraine (2010-2011). The report to the COSPAR. Academ Periodyka, Kyiv, pp 102-105. 
Lee, L.-H., Cheah, Y.-K., Nurul Syakima, A.M., Shiran, M.S., Tang, Y.-L., Lin H.-P., Hong, K. (2012) Analysis of Antarctic proteobacteria by PCR fingerprinting and screening for antimicrobial secondary metabolites. Genetics and Molecular Research 11(2):1627-1641.

Lovelock, J.E. (1965) A physical basis for life detection experiments. Nature 207:568-570.

Meeßen, J., Wuthenow, P., Schille, P., Rabbow, E., de Vera, J.-P., Ott, S. (2015) Resistance of the LichenBuellia frigidato simulated space conditions during the preflight tests for BIOMEX — viability assay and morphological stability. Astrobiology 15(8):1-15.

Miller, J.H. (1972) Experiments in molecular genetics. Cold Spring Harbor Laboratory, 466.

Mytrokhyn, O.V., Bogdanova, S.V., Shumlyanskyy, L.V. (2003). Anorthosite rocks of Fedorivskyy suite (Korosten Pluton, Ukrainian Shield), in: Current Problems in Geology. Eds. Kyiv National University, Kyiv, pp.53-57.

Nobles, D.R. Romanovicz, D.K., Brown R.M.Jr. (2001) Cellulose in cyanobacteria. Origin of vascular plant cellulose synthase? Plant Physiol 127:529-542.

Ovcharenko, L.P., Reva, O.N., Zaets, I.E., Kukharenko, O., Burlak, O.P., Podolich, O.V., de Vera, J.-P., Kozyrovska, N.O. (2013) DNA metabarcoding of complex microbial communities promising for space research. In: Abstract Book $13^{\text {th }}$ Ukrainian conference on Space Research (Yevpatoria, September 2-7, 2013), Kyiv, 2013, p 84.

Podolich, O., Zaets, I., Kukharenko, O., Orlovska, I., Reva, O., Khirunenko, L., Sosnin, M., Hayidak, A., Shpylova, S., Rohutskyy, I., Kharina, A., Skoryk, M., Kremenskoy, M., Klymchuk, D., Demets, R., de Vera, J.-P., Kozyrovska, N. The first space-related study of a kombucha multimicrobial cellulose-forming community: preparatory laboratory experiments. Submitted to Origins of Life and Evaluation of Biospheres, in press.

Rabbow, E., Rettberg, P., Barczyk, S., Bohmeier, M., Parpart, A., Panitz, C., Horneck, G., von Heise-Rotenburg, R., Hoppenbrouwers, T., Willnecker, R., Baglioni, P., Demets, R., Dettmann, J., Reitz, G. (2012) EXPOSE-E: an ESA astrobiology mission 1.5 years in space. Astrobiology 12(5):374-386.

Rabbow, E., Rettberg, P., Barczyk, S., Bohmeier, M., Parpart, A., Panitz, C., Horneck, G., Burfeindt, J., Molter, F., Jaramillo, E., Pereira, C., Weiß, P., Willnecker, R., Demets, R., Dettmann, J., Reitz, G. (2015) The astrobiological mission EXPOSE-R on board of the International Space Station. International Journal of Astrobiology 14(1):3-16.

Reva, O.N., Zaets, I.E., Ovcharenko, L.P., Kukharenko, O., Shpylova, S., Podolich, O.V., de Vera, J.P., Kozyrovska, N.O. (2015) Metabarcoding of the kombucha microbial community grown in different microenvironments. AMB Express 5:35-42.

Romling, U., Galperin, M.Y. (2015) Bacterial cellulose biosynthesis: diversity of operons, subunits, products, and functions. Trends Microbiol 23(9):545-557. 
Ross, P., Mayer, R., Benziman, M. (1991) Cellulose biosynthesis and function in bacteria. Microbiol Rev 55:35-58.

Saha, R., Pohorille, A., Chen, I.A. Molecular Crowding and Early Evolution. Orig Life Evol Biosph. 44(4):319-24.

Zaetz, I.E. (2009) Modification of heavy metal accumulation by plants with bacterial consortium. Manuscript. Thesis for Candidate's degree in Biological Sciences by speciality 03.00.20 - Biotechnology. - Institute of Molecular Biology and Genetics of National Academy of Sciences of Ukraine, Kyiv, pp 151.

Zaets, I., Podolich, O., Kukharenko, O., Reshetnyak, G., Shpylova, S., Sosnin, M., Khirunenko, L., Kozyrovska, N., de Vera, J.-P. (2014) Bacterial cellulose may provide the microbial-life biosignature in the rock records. Adv Space Res 53(5):828-835. 
Table S1. Kombucha microbial community survival and biofilm formation after Experimental Verification Tests (EVT)

\begin{tabular}{|c|c|c|c|c|c|}
\hline \multicolumn{2}{|c|}{ Exposure Experiments } & \multirow{3}{*}{$\begin{array}{l}\text { Bacteria } \\
\text { survival }\end{array}$} & \multirow{3}{*}{$\begin{array}{l}\text { Yeast } \\
\text { survival }\end{array}$} & \multicolumn{2}{|c|}{ Biofilm formation } \\
\hline Indicators & $\begin{array}{l}\text { Conditions and duration } \\
\text { of treatments }\end{array}$ & & & \multirow[t]{2}{*}{$\begin{array}{l}\text { a week since } \\
\text { pills inoculation }\end{array}$} & \multirow{2}{*}{$\begin{array}{l}\text { a month } \\
\text { since pills } \\
\text { inoculation }\end{array}$} \\
\hline \multicolumn{2}{|l|}{ EVT1 } & & & & \\
\hline \multirow[t]{2}{*}{$\begin{array}{l}\text { Vacuum, } 10^{-5} \\
\mathrm{~Pa}\end{array}$} & $\begin{array}{l}1 \mathrm{~h} \text {, pressure: } 3.86 \times 10^{-} \\
\pm 0.12 \mathrm{~Pa}\end{array}$ & + & + & - & \pm \\
\hline & $\begin{array}{l}7 \mathrm{~d} \text {, pressure: } 8.50 \times 10^{-} \\
\pm 0.12 \mathrm{~Pa}\end{array}$ & + & + & - & \pm \\
\hline \multirow{2}{*}{$\begin{array}{l}\text { Mars } \\
\text { atmosphere } \\
\left(\mathrm{CO}_{2} \text { gas }\right. \\
\text { composition }), \\
10^{3} \mathrm{~Pa}\end{array}$} & $\begin{array}{l}1 \mathrm{~h}, \text { pressure: } 6.08 \mathrm{x} \\
10^{2} \pm 0.12 \mathrm{~Pa}\end{array}$ & + & + & - & \pm \\
\hline & $\begin{array}{l}7 \mathrm{~d} \text {, pressure: } 6.00-6.6 \\
\mathrm{x} 10^{2} \pm 0.12 \mathrm{~Pa}\end{array}$ & + & + & - & \pm \\
\hline $\begin{array}{l}\text { Temperature } \\
\text { cycling, from - } \\
10{ }^{\circ} \mathrm{C} \text { to }+45 \\
{ }^{\circ} \mathrm{C}\end{array}$ & $\begin{array}{l}66 \text { cycles, } 8 \mathrm{~h} \text { each }(2 \mathrm{~h} \\
\text { at }-10{ }^{\circ} \mathrm{C} \pm 1^{\circ} \mathrm{C}, 2 \mathrm{~h} \text { at } \\
+45^{\circ} \mathrm{C} \pm 1^{\circ} \mathrm{C}, 2 \mathrm{~h} \text { each } \\
\text { for cooling and heating) }\end{array}$ & + & + & + & + \\
\hline \multirow{2}{*}{$\begin{array}{l}\text { Temperature } \\
\text { max and min }\end{array}$} & $1 \mathrm{~h},-25^{\circ} \mathrm{C}$ & + & + & + & + \\
\hline & $1 \mathrm{~h},+60^{\circ} \mathrm{C}$ & + & + & + & + \\
\hline \multirow{5}{*}{$\begin{array}{l}\text { Monochromatic } \\
\text { irradiation } 254 \\
\mathrm{~nm} \text {. }\end{array}$} & $8 \mathrm{~J} / \mathrm{m}^{2}, 1 \mathrm{sec}$ & + & + & - & + \\
\hline & $100 \mathrm{~J} / \mathrm{m}^{2}, 12 \mathrm{sec}$ & + & + & - & + \\
\hline & $1000 \mathrm{~J} / \mathrm{m}^{2}, 2 \mathrm{~min} 5 \mathrm{sec}$ & + & + & - & + \\
\hline & $1500 \mathrm{~J} / \mathrm{m}^{2}, 18 \mathrm{~min}$ & + & + & - & + \\
\hline & $\begin{array}{l}10000 \mathrm{~J} / \mathrm{m}^{2}, 20 \mathrm{~min} 50 \\
\mathrm{sec}\end{array}$ & + & + & - & + \\
\hline $\begin{array}{l}\text { Laboratory } \\
\text { control }\end{array}$ & without treatment & + & + & + & + \\
\hline $\begin{array}{l}\text { Transportation } \\
\text { control } \\
\text { (to Cologne } \\
\text { and back) }\end{array}$ & without treatment & + & + & + & + \\
\hline \multicolumn{6}{|l|}{ EVT-2 run 1} \\
\hline \multirow{4}{*}{$\begin{array}{l}\text { Polychromatic } \\
\text { irradiation 200- } \\
400 \mathrm{~nm} \text {. }\end{array}$} & $14000 \mathrm{~J} / \mathrm{m}^{2}, 3 \mathrm{~h}$ & + & + & - & + \\
\hline & $140000 \mathrm{~J} / \mathrm{m}^{2}, 30 \mathrm{~h}$ & - & - & - & - \\
\hline & $450000 \mathrm{~J} / \mathrm{m}^{2}, 99 \mathrm{~h}$ & - & - & - & - \\
\hline & $780000 \mathrm{~J} / \mathrm{m}^{2}, 148 \mathrm{~h}$ & - & - & - & - \\
\hline $\begin{array}{l}\text { Laboratory } \\
\text { control }\end{array}$ & without treatment & + & + & + & + \\
\hline $\begin{array}{l}\text { Transportation } \\
\text { control } \\
\text { (to Cologne } \\
\text { and back) }\end{array}$ & without treatment & + & + & + & + \\
\hline
\end{tabular}

Note. " \pm " means that biofilm did not contain cellulose 

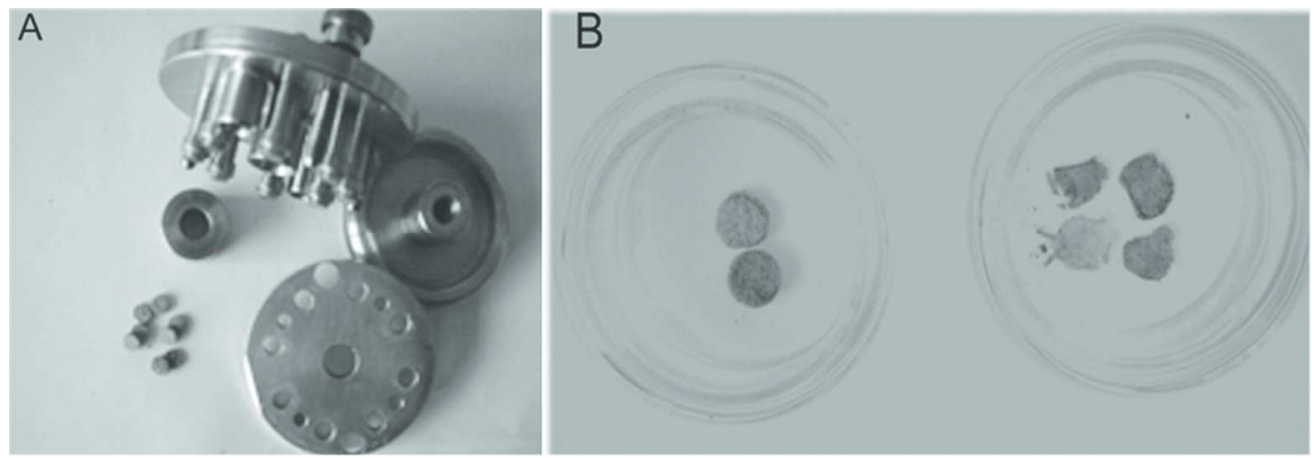

$85 \times 29 \mathrm{~mm}(300 \times 300 \mathrm{DPI})$

FIG. S1. Device for fabrication of bio0 ineral samples (A) and a view of KMC samples containing dry cellulose pellicle (B). 